ON THE RECORD

“He's attractive.

And my son loves

the fact he was an

astronaut."

A deep-thinking $C$ anadian voter describes why she might vote for Liberal parliamentary candidate Marc Garneau.

"The Americans are going to be last on the

list, I can tell you."

A group of researchers at Britain's Mill Hill lab discuss how they will share their samples after US news coverage played down the fact that theywere the ones to isola te and grow the Turkish bird-flu virus.

Sources: Montreal Gazette, The independent

\section{SCORECARD}

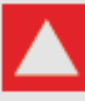

Extreme tourism For just US\$334 a person, Ukrainian travel agents offer an all-inclusive holiday to Chernobyl to mark the 20th anniversary of what they call the "worst environmental disaster in history".

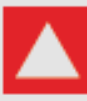

\section{Scientific vanity} Go one better than Googlingyourself:new

features on Elsevier's Scopus service make it easier to get daily updates on who is citing your work - and that of your competitors.

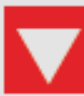

Plant patents Local farmers are calling on the University of Hawaii to give up its patents on three kinds of taro, the root that forms the basis of much Hawailian native cuisine and culture.

\section{NUMBER CRUNCH}

NASA's Stardust mission retumed to Earth last weekend bringing with it samples snared from a comet (see page 255). It was quite atrip:

\section{6 billion kilometres} were travelled by Stardust on its joumey to Comet Wild 2 and back.

7 years is the time it took the probe to do the round trip.

Less than 0.1 gram is the estimated amount of cometary particles collected by Stardust.

\title{
Journals submit to scrutiny of their peer-review process
}

Results are starting to come in from what may be the largest-ever study of the practice of peer review.

Three prestigious medical journals - The Lancet, Annals of Internal Medicine and the $B M J$ - threw open their doors and allowed the study team unprecedented access. Researchers were able to see all relevant paperwork, including confidential referee reports, and were permitted to video editorial meetings. The result is a data set that documents the passage of more than 1,000 papers through the peer-review process, from submission to publication or, far more often, rejection (see 'The data set').

Having cameras in meetings was a bizarre experience, says Richard Horton, editor of The Lancet - he says it felt like the researchers were making a reality television show about medical journals. But Horton adds the process was well worth it, as "this is a huge study, which makes the results very reliable.

"It felt like the making a reality television show." researchers were

The data set

1,107 papers wereexamined

$100+$ hour s of meetings were taped for each journal

\section{6 editor 5 were interviewed}

compared the 68 manuscripts that were published with those rejected, they found no evidence of bias towards statistically significant results. "Hopefully, this will encourage authors to submit," says Kirby Lee, an expert in evidence-based health care and an author on the

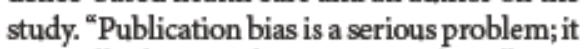
can really skew results in meta-analyses."

Other findings also tend towards the quantitative (see 'Dissecting peer review'). But peer-review experts say the qualitative parts of the study, which had to wait for transcripts of the videos, are likely to prove more interesting. ${ }^{\alpha}$ Peer review can be a complex deci-

Those results, the first of which were submitted for publication earlier this month, give a qualified thumbs up to current editorial practices. They may also go some way to dispelling widely held doubts about peer review.

One question investigated by the study authors, who are based at the University of California, San Francisco, is whether editors favour positive results over null findings. Many researchers do not attempt to publish negative results, assuming that editors are not interested. This is a particular problem in medicine, because the efficacy of a drug will be exaggerated if trials reporting negative results are not published.

But when the California researchers

\section{Dissecting peer review}

What the researchers have discovered so far.

- There is no right answer - referees often disagree with each other.

- Authors have tocome clean - they frequently fail to disclose funding sources and potential conflicts of interest in submittedmanuscripts until asked to doso by joumal editors.

- It separates the wheat from the chaffthemethodological quality of accepted articles is higher than that of rejected ones. sion-making process involving lots of people," notes Sara Schroter, who studies journal practice at the BMJ Publishing Group in London. "If you want to understand why something happens it is best to conduct qualitative research."

Lee says that the qualitative study should shed light on issues such as the criteria that editors use when deciding to review or reject articles, as well as how interactions at editorial meetings help shape decisions about publication. "We want to identify sources of systematic bias in the editorial review process that may result in a publication record that is not representative of the true distribution of study findings submitted to each journal," he says.

Horton adds that the study could also help improve public understanding of peer review. The timing is good, he says, because questions about editorial standards are being asked in the wake of the scandal surrounding the South Korean stem-cell scientist Woo Suk Hwang, who published two widely acclaimed papers later found to have been faked. Horton says that some criticisms, such as failure to spot fabricated data, stem from a lack of understanding about what peer review can and cannot do.

"Peer review is a black box to the public and politicians," he says. "Unless we open up that box we are going to get misperceptions." Jim Giles 